\title{
Pelatihan Pembelajaran Aplikasi Cerdas Cermat Unik (ACCU) bagi Para Siswa SDN Pabean 1 Sedati Sidoarjo
}

\author{
Titus Kristanto ${ }^{1}$, Rachman Arief ${ }^{2}$ \\ ${ }^{1}$ Rekayasa Perangkat Lunak, Fakultas Teknologi Informasi dan Industri, Institut Teknologi Telkom \\ Surabaya - Jl. Gayungan PTT No. 17-19 Surabaya \\ ${ }^{2}$ Teknik Informatika, Fakultas Teknologi Informasi, Institut Teknologi Adhi Tama Surabaya - Jl. Arief \\ Rachman Hakim No. 100 Surabaya \\ E-mail: ${ }^{1}$ tintus.chris@gmail.com, ${ }^{2}$ ramanarif@gmail.com. 085730370856, 085731102722
}

\begin{abstract}
ABSTRAK
Pendidikan merupakan proses untuk mendewasakan seseorang dari berbagai sektor. Pendidikan dapat ditempuh dari berbagai proses baik pendidikan formal, informal, maupun non-formal. Pada usia anak 0-6 tahun, merupakan periode yang tepat otak anak sedang berkembang dengan pesat. Sehingga dapat menyerap secara cepat baik yang didengar maupun yang dilihat. Berdasarkan data dari Dinas Pendidikan, hasil nilai Ujian Nasional untuk jenjang SD mengalami penurunan dibandingkan dengan tahun-tahun sebelumnya. Penurunan nilai Ujian Nasional disebabkan siswa kurang tertarik untuk belajar. Supaya siswa tertarik untuk belajar, diperlukan inovasi berupa game edukasi sebagai media pembelajaran. Game edukasi tersebut ditujukan bagi para siswa kelas VI SD untuk menghadapi Ujian Nasional. Hasil dari pembuatan game edukasi adalah para siswa agar lebih nyaman bermain game sambil belajar, sehingga dapat menambah wawasan dan pengetahuan, serta memperkuat daya ingat siswa.
\end{abstract}

Kata kunci : game edukasi; pendidikan; ujian nasional; siswa SD

\section{ABSTRACT}

Education is a process to mature someone from various sectors. Education can be taken from various processes both formal, informal and non-formal education. At the age of children 0-6 years, is the right period of the child's brain is growing rapidly. So that it can absorb quickly both heard and seen. Based on data from the Education Authorities, the results of the National Examination for elementary school have decreased compared to previous years. The decline in the value of the National Examination is caused by students being less interested in learning. In order for students to be interested in learning, innovation is needed in the form of educational games as learning media. The educational game is intended for grade VI elementary school students to face the National Examination. The result of making educational games is that students are more comfortable playing games while learning, so they can add insight and knowledge, and strengthen student's memory.

Keywords : educational games; education; national examination; elementary school students

\section{PENDAHULUAN}

Pendidikan merupakan proses untuk mendewasakan seseorang dari berbagai sektor. Pendidikan dapat ditempuh dari berbagai proses baik pendidikan formal, informal, maupun nonformal [1]. Dunia

Cara Mengutip : Kristanto, T., Arief, R., (2019). Pelatihan Pembelajaran Aplikasi Cerdas Cermat Unik (ACCU) bagi Para Siswa SDN Pabean 1 Sedati Sidoarjo. JAST: Jurnal Aplikasi Sains dan Teknologi, 3 (1), 17-23. 
pendidikan di Indonesia terbagi menjadi 3 jenjang yaitu jenjang SD, SMP, dan SMA.

Pada usia anak 0-6 tahun, merupakan periode dimana otak anak sedang berkembang dengan pesat. Sehingga setiap anak mampu menyerap secara cepat dengan segala sesuatu yang didengar atau yang dilihat [2]. Usia dini sekitar usia 0-6 tahun merupakan usia yang tepat untuk diberikan dengan berbagai konsep kehidupan untuk bekal kehidupan selanjutnya [3]. Pendidikan usia dini merupakan penentu dari pembentukan karakter seseorang dari kehidupan berbangsa dan bernegara [4].

Berdasarkan data dari Dinas Pendidikan Provinsi Jawa Timur, hasil Ujian Nasional (UN) pada jenjang SD/MI, SMP/MTs, SMA/SMK/MA pada tahun 2016 mengalami penurunan dibandingkan dengan tahun-tahun sebelumnya [5]. Ketiga mata pelajaran yang diujikan pada jenjang SD/MI yaitu Bahasa Indonesia, Matematika, dan Ilmu Pengetahuan Alam (IPA). Nilai rata-rata total nilai yang diujikan pada Ujian Nasional (UN) adalah 218,05 atau rata-rata $72,68 \%$. Penuruan nilai Ujian Nasional pada jenjang SD/MI disebabkan banyak faktor, salah satunya adalah siswa kurang niat atau kurang tertarik untuk belajar.

Pada umumnya, kegiatan membaca buku sangat membosankan, sehingga siswa lebih tertarik bermain game. Dikarenakan bermain game, lebih asyik dan lebih menyenangkan dibandingkan membaca buku. Sehingga wawasan siswa sangat kurang dan menjadi penyebab nilai UN turun.
Di era milenial saat ini, game di mata masyarakat khususnya siswa menjadikan sebagai media penghibur dibandingkan media pembelajaran. Ada beberapa macam sifat dasar dari game yaitu game yang menantang (challenging), game membuat ketagihan (addited), dan game yang menyenangkan (fun) [6].

Bagi siswa yang menyukai permainan modern, dapat berdampak negatif apabila permainan tersebut tidak bersifat edukasi. Sehingga diperlukan game edukasi yang dapat digunakan sebagai media pembelajaran yang mampu memotivasi siswa agar tertarik untuk belajar.

Berdasarkan hasil penelitian sebelumnya, game edukasi dapat menunjang proses pendidikan [7][8]. Game edukasi juga unggul dalam beberapa aspek dibandingkan metode pembelajaran konvensional [9]. Salah satu keunggulan adalah dapat meningkatkan daya ingat sehingga siswa dapat menyimpan materi pelajaran dalam waktu lebih lama dibandingkan metode pengajaran konvensional [10].

Dari permasalahan tersebut, perlu adanya pembelajaran ilmu pengetahuan melalui media game yang dibuat. Game yang dibuat menggunakan web dan dimainkan secara berkelompok. Tiap kelompok dimaikan dengan 2 orang yang akan beradu dengan kecepatan, ketangkasan, dan ketepatan dalam menjawab sejumlah pertanyaan yang diberikan. 
Game tersebut ditujukan bagi para siswa SD kelas VI SDN Pabean 1 Sedati Sidoarjo dengan jumlah masing-masing 30 siswa setiap kelasnya. Pemilihan siswa kelas VI SD adalah berdasarkan kemampuan siswa SD yang sudah bisa mengoperasikan komputer, dan mempersiapkan siswa dalam menghadapi Ujian Nasional (UN).

Harapan dari pembuatan game adalah membuat siswa SD lebih nyaman untuk bermain game sambil belajar, sehingga dapat menambah wawasan dan pengetahuan, serta memperkuat daya ingat siswa.

Luaran dari kegiatan pengabdian adalah aplikasi game edukasi yang dapat digunakan sebagai media bantu pembelajaran bagi para siswa SDN Pabean 1 Sedati Sidoarjo dalam menghadapi Ujian Nasional (UN). Selain luaran berupa produk aplikasi, juga terdapat luaran berupa laporan akhir pengabdian dan disebarluaskan ke pihakpihak terkait dengan kegiatan pelatihan, misalkan dari pihak kampus, pihak sekolah, Ristekdikti, dan sebagainya [11].

\section{METODE KEGIATAN}

Pelaksanakan kegiatan berlokasi di SDN Pabean 1 Sedati Sidoarjo, beralamat di Jl. Raya Pabean No. 69 Sedati Sidoarjo. SDN Pabean 1 Sedati Sidoarjo merupakan sekolah bertaraf Nasional yang berada di Kabupaten Sidoarjo. Lokasi sekolah strategis dekat dengan Bandara Internasional Juanda Surabaya dan mudah dijangkau dengan angkutan umum. Pada Gambar 1 merupakan SDN Pabean 1 Sedati Sidoarjo tampak dari luar.

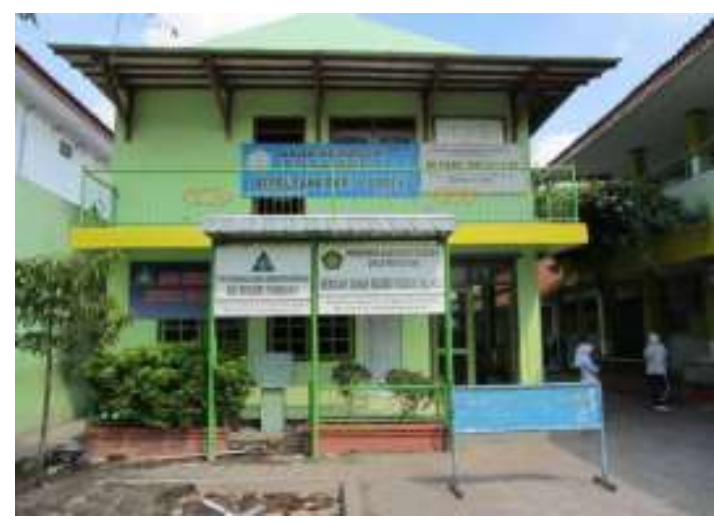

Gambar 1. SDN Pabean 1 Sedati Sidoarjo tampak dari luar

Adapun serangkaian tahapan yang dilakukan dalam kegiatan pelatihan yaitu :

1. Mengajukan proposal dan perizinan tempat serta penjadwalan kegiatan pelatihan.

Pada tahap ini, tim pengabdian melakukan perizinan kepada Kepala SDN Pabean 1 Sedati Sidoarjo terkait penggunaan Lab Komputer sebagai tempat pelatihan pengabdian serta pengaturan jadwal bagi siswa SD kelas VI.

2. Survey lokasi Laboratorium Komputer Pada tahap ini, tim pengabdian melakukan survey ke Lab Komputer SDN Pabean 1 Sedati Sidoarjo yang digunakan sebagai tempat pelaksanaan kegiatan pengabdian. Selain melihat kondisi Lab Komputer, juga ingin mengetahui kebutuhan tambahan yang diperlukan dalam kegiatan pelatihan.

3. Pembuatan Aplikasi Game Edukasi Pada tahap ini, tim pengabdian membuat aplikasi game edukasi yang diberikan kepada para siswa kelas VI SDN Pabean 1 Sedati Sidoarjo sebagai media pembelajaran baru.

4. Pemasangan instalasi aplikasi game edukasi 
Pada tahap ini, tim pengabdian melakukan pemasangan instalasi game edukasi pada komputer di Lab Komputer SDN Pabean 1 Sedati Sidoarjo. Selain pemasangan instalasi game edukasi, dilakukan konfigurasi dan pemasangan kebutuhan tambahan agar aplikasi dapat digunakan secara interaktif dan berkelompok.

5. Perencanaan skenario dan uji coba aplikasi

Pada tahap ini, tim pengabdian merencanakan skenario proses pelaksanaan kegiatan pelatihan berupa uji coba aplikasi game edukasi.

\section{KARYA UTAMA}

Karya utama yang dihasilkan dari kegiatan pengabdian adalah sebuah program aplikasi game edukasi yang digunakan bagi para siswa kelas 5 SDN Pabean 1 Sedati Sidoarjo. Aplikasi game edukasi digunakan sebagai media pembantu dalam pembelajaran guna mempersiapkan para siswa dalam menghadapi Ujian Nasional (UN). Pada Gambar 2 menggambarkan suasana kegiatan pelatihan pengabdian.

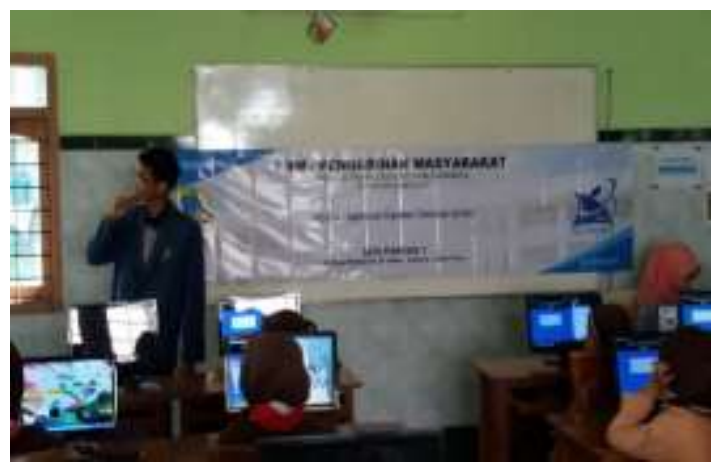

Gambar 2. Suasana kegiatan pelatihan pengabdian
Aplikasi game edukasi tersebut diinstall pada laboratorium komputer, Sehingga memudahkan para siswa mengoperasikan aplikasi game edukasi tersebut.

\section{ULASAN KARYA}

Aplikasi game edukasi dibuat berdasarkan soal-soal pada mata pelajaran yang diujikan di Ujian Nasional (UN) yaitu Matematika, Bahasa Indonesia, dan Ilmu Pengetahuan Alam (IPA). Soal-soal tersebut masing-masing terdiri dari 30-50 soal multiple choice (pilihan ganda) dengan mode soal random (acak), sehingga para siswa tidak dengan mudah menghafalkan soal dan kunci jawaban yang sudah pernah dikerjakan.

Sebelum soal-soal tersebut diujicobakan kepada para siswa, maka para guru diberikan pelatihan terlebih dahulu bagaimana cara memasukkan soalsoal yang diujikan pada Ujian Nasional (UN) ke dalam aplikas game edukasi. Semua para guru terlibat pada pelatihan tersebut untuk memasukkan soal ke aplikasi. Selain memasukkan soal, para guru juga memasukkan kunci jawaban dari soal yang diujikan. Dengan memasukkan atau memberikan kunci jawaban, membantu para siswa untuk mengingat jawaban yang benar.

Setelah memberikan pelatihan ke guru-guru SD, maka pelatihan selanjutnya ke siswa-siswi SD kelas VI. Pelatihan untuk para siswa SD dilakukan pada hari berikutnya. Sebelum dilakukan pelatihan, para siswa diberikan pengarahan dan perkenalan terlebih dahulu dari tim pengabdian, dapat dilihat pada Gambar 3 dan Gambar 4. 


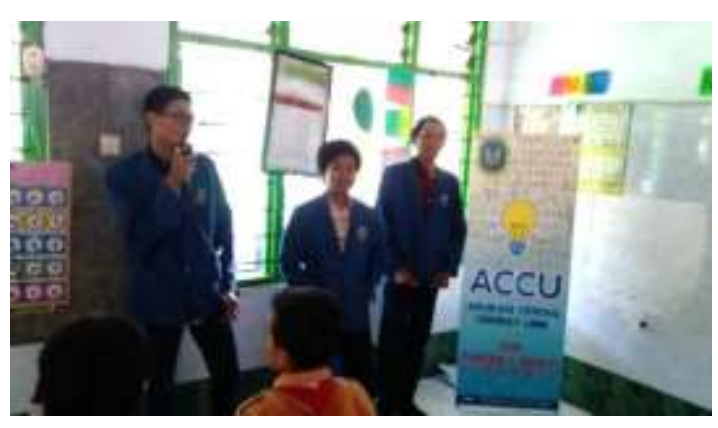

Gambar 3. Pengarahan tim pengabdian

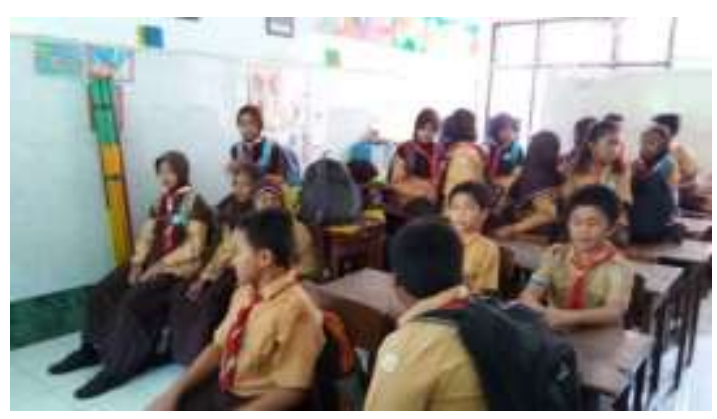

Gambar 4. Suasana pengarahan sebelum pelatihan

Setelah para siswa diberikan pengarahan, para siswa diarahkan menuju lab komputer untuk melakukan pelatihan, dapat dilihat pada Gambar 5.

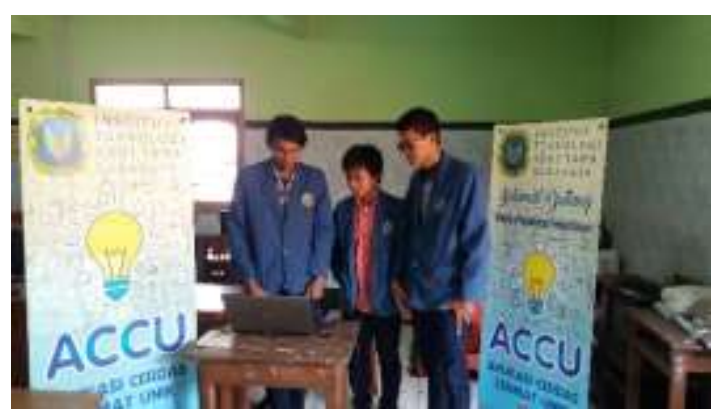

Gambar 5. Suasana pelatihan di lab komputer

Pelatihan untuk para siswa dilakukan mulai pagi sampai sore. Menjelang sesi akhir, diberikan hadiah dan kenang-kenangan bagi para siswa yang bisa menyelesaikan tugas hingga tuntas, dapat dilihat pada Gambar 6, 7, dan 8 .

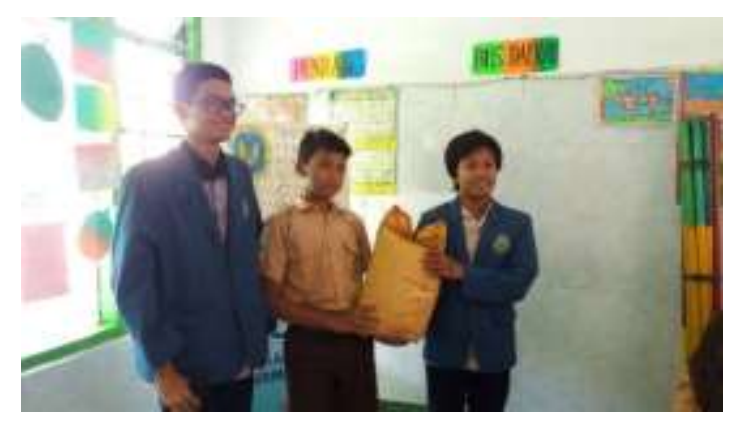

Gambar 6. Pembagian hadiah juara ke-1

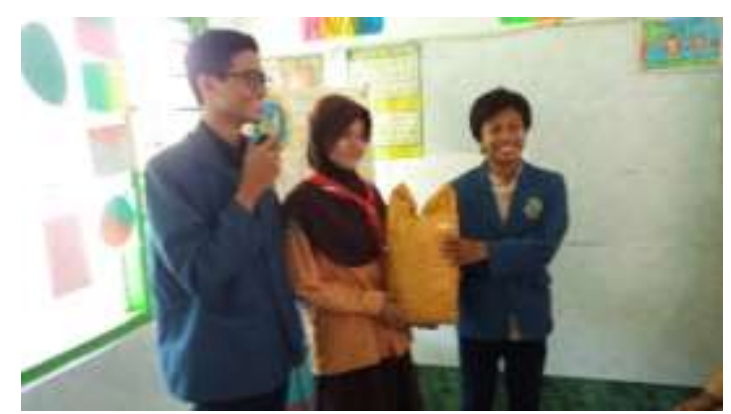

Gambar 7. Pembagian hadiah juara ke-2

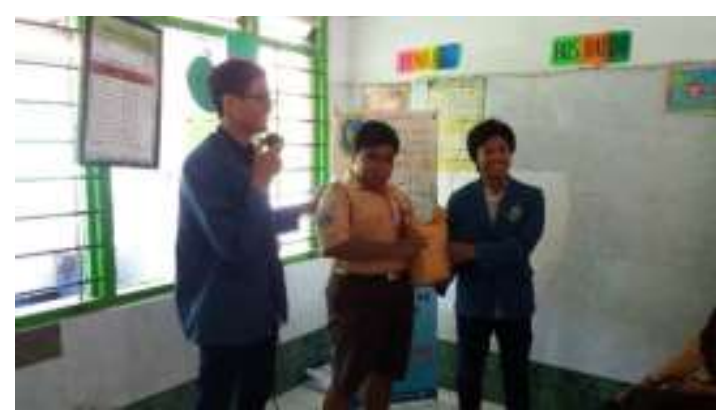

Gambar 8. Pembagian hadiah juara ke-3

\section{DAMPAK DAN MANFAAT KEGIATAN}

Dampak dan manfaat dari kegiatan pelatihan pengabdian masyarakat [12] adalah memberikan wawasan dan pengetahuan bagi para siswa sebagai media pembelajaran untuk persiapan menghadapi Ujian Nasional (UN).

Pada kegiatan pengabdian, tim pengabdian didampingi oleh guru TIK (Teknologi Informasi dan Komunikasi) sebagai perwakilan dari SDN Pabean 1 Sedati Sidoarjo. Guru TIK memberikan 
sepatah dua patah kata terkait kegiatan pelatihan pengabdian. Para guru berterima kasih pada tim pengabdian karena telah membantu para siswa sebagai media pembelajaran dalam menghadapi Ujian Nasional (UN).

\section{KESIMPULAN}

Dari kegiatan pelatihan pengabdian masyarakat yang dilaksanakan di SDN Pabean 1 Sedati Sidoarjo dapat disimpulkan sebagai berikut :

1. Kegiatan pelatihan mendapatkan respon positif dari para guru dan para siswa, dibuktikan dengan antusias dan partisipasi dari siswa kelas VI.

2. Membantu para siswa dalam memahami mata pelajaran yang diujikan di Ujian Nasional (UN).

\section{PENGHARGAAN}

Tim pengabdian masyarakat mengucapkan terima kasih kepada Direktorat Jenderal Pembelajaran dan Kemahasiswaan (Ditjenbelmawa), Kementerian Riset, Teknologi, dan Pendidikan Tinggi (Kemenristekdikti) yang telah mempercayai dan membiayai kegiatan Program Kreativitas Mahasiswa Pengabdian Kepada Masyarakat (PKMM). Tim pengabdian juga mengucapkan terima kasih kepada Wakil Rektor III, LPPM, dan Kepala SDN Pabean 1 Sedati Sidoarjo yang telah mendukung kegiatan PKM-M, termasuk kegiatan monitoring dan evaluasi (Monev) Eksternal yang dilaksanakan di Kampus Institut Teknologi Sepuluh Nopember (ITS).

\section{DAFTAR PUSTAKA}

[1] S. Bahri, "Implementasi Pendidikan Karakter dalam Mengatasi Krisis Moral di Sekolah," Ta'Allum, vol. 03, no. 01, pp. 57-76, 2015.

[2] T. Rustini, "Pendidikan Karakter Anak Usia Dini," Cakrawala Dini J. Pendidik. Anak Usia Dini, vol. 3, no. 1, 2012.

[3] I. B. Maryatun, "Peran Pendidik PAUD Dalam Membangun Karakter Anak," J. Pendidik. Anak, vol. 5, no. 1, pp. 1-9, 2016.

[4] U. Rohmah, "Pengembangan Karakter Pada Anak Usia Dini (AUD)," Al-Athfal J. Pendidik. Anak, vol. 4, pp. 85-102, 2018.

[5] AntaraNews.Com, "Nilai UN SD_SMP_SMA Jatim Alami Penurunan - ANTARA News," Surabaya, 2016.

[6] Dannu Teygar Harry Anjas Pratama, "Game Kecepatan Berhitung pada Android," Universitas Muhammadiyah Malang, 2016.

[7] R. E. Clark and S. Choi, "Five Design Principles for Experiments on the Effects of Animated Pedagogical Agents," J. Educ. Comput. Res., vol. 32, no. 3, pp. 209-225, 2005.

[8] R. E. Clark, "Evaluating the Learning and Motivation Effects of Serious Games.” 2006.

[9] A. V. Vitianingsih, "Game Edukasi Sebagai Media Pembelajaran Pendidikan Anak Usia Dini," $J$. Inform. Merdeka Pasuruan, vol. 1, no. 1, pp. 46-58, 2016. 
[10] D. Clark, "Games and e-learning," 2006.

[11] T. Kristanto, I. Ratniarsih, D. P. E. Laksmiyanti, and Y. A. Sabtalistia, "Pelatihan dan Penyuluhan Usaha Otak-Otak Ikan di Perumahan Dinas PT KAI Kota Surabaya," J-Dinamika J. Pengabdi. Masy., vol. 3, no. 2, pp. 176-179, 2018.

[12] J. Rohmah and N. Azizah, "Program Pengabdian Masyarakat Melalui Pengolahan Buah Kersen (Muntingia calabura L.)," JAST J. Apl. Sains dan Teknol., vol. 2, no. 1, pp. 12-21, 2018. 